\title{
SYNERGY OF MULTILINGUALISM AND MULTICULTURALISM FROM THE PERSPECTIVE OF INTERNATIONALIZATION OF HIGHER POFESSIONAL EDUCATION
}

\author{
Liu Changyuan ${ }^{1}$, Maria Kopylovskaya ${ }^{2}$, Svetlana Rubtsova ${ }^{3}$, Tatiana Dobrova ${ }^{4}$ \\ ${ }^{1}$ Harbin Institute of Technology, ${ }^{2,3,4}$ Saint Petersburg State University \\ E-Mail: ${ }^{1}$ cyliuchina@163.com, ${ }^{2}$ mkopska@mail.ru, ${ }^{2}$ s.rubtcova@ spbu.ru, t.dobrova@spbu.ru
}

\begin{abstract}
The article deals with the issue of internationalization of higher education, in particular, in the sphere of language pedagogy. The study is based on the materials of the research conducted within the framework of the academic mobility project exercised 2018-2019 in Saint Petersburg State University and in Harbin Institute of Technology (visited November, 2018). The process of internationalization is viewed through the prism of such intercultural communication concepts as multilingualism and multiculturalism and their influence on teaching and learning practices. In real life English as lingua franca is used by representatives of different linguistic and cultural identities to communicate with representatives of professional and academic communities for whom English is also a foreign language, thus teaching English as lingua franca requires professionals who are not native speakers possessing the experience of professional and intercultural communication in the English language rather than just native speakers' language experience. The peculiarities of teaching in the above-mentioned universities were revealed with the help of questionnaires for both university teachers and students concerning learners' practices in the digital environment. The authors set up the hypothesis that the results serve as an authentic manifestation of intercultural communication in students' virtual activities in social networks and in browsing the Internet for relevant information both in Russia and China.
\end{abstract}

Key words: internationalization of higher education, intercultural communication, multilingualism, multiculturalism, learners' digital environment

\section{INTRODUCTION}

The phenomenon of cooperation effect has been studied since early ages and labelled as synergy. The Greek word 'synergos' meaning 'working together' denotes the outcomes which supersedes the results obtained in case of individual performance. Therefore, the initial goal set by the research team was to study the synergetic effect of the impact of multiculturalism and multilingualism on learning and acquisition of the concepts and categories of intercultural communication in the context of a particular example of Sino-Russian cooperation. The research was centered upon higher education language pedagogy as the English language has become of particular importance operating as a metadiscipline necessary for the professional development of a specialist, i.e. in any sphere of knowledge and any occupation. 
To understand the nature and current trends of internationalization in higher language education the given research was focused on teaching and learning processes in the educational environment of two higher educational establishments in the People's Republic of China (PRC) and Russian Federation (RF): the Harbin Institute of Technology, and Saint-Petersburg State University, both involved in educating students from PRC for acting as specialists in the XXI century economies and capable of communicating their messages at the international level, i.e. ready for intercultural communication.

The history of the cooperation in the sphere of education dates back to the first years of the Soviet State when the intense interest towards the knowledge and expertise of Russian specialists led to inviting them in numbers, moreover, having not determined their attitudes towards new political situation in Russia there was a huge wave of immigrants from Russia to Harbin and Shanghai, both becoming vital immigration centers. Those circumstances laid the grounds for the fusion of languages and cultures at the early 1920s and with some ebbs and flows continued further on.

The cooperation in the sphere of education seems to have been most productive as China not only invited a great number of technical specialists to assist them in building new factories and machines, but also to prepare specialist capable of doing it in future. The cooperation between such higher educational institutions as the Harbin Institute of Technology (HIT) and Saint Petersburg State University (SPbSU) is one of the best examples of those practices.

It is important to note that students from the PRC dominate the foreign studentship in $\mathrm{SPbSU}$ and a great number of other universities around the RF. Therefore, it is worth distinguishing them into a specific and meaningful group of learners who learn Russian as a second language in the Russian-speaking environment and English as a foreign language and the main language of intercultural communication. Thus, the factor of comparing and contrasting learning environments, the specific features of teaching cultures offset by the trends of digitalization represent the core of the research.

However, in the era of information when the technical expertise and any other academic knowledge is to be verified and often presented globally the learners need the instrument of communication, which is not only Russian or Chinese but international English. Leaving the questions of the role of the Russian and Chinese language systems for another detailed research, the paper focuses on the existing need - the need in intercultural communicative competence. The research was conducted to consider the patterns capable to promote greater intercultural communicative efficiency in the context of the given academic communities.

Therefore, the major goal of the research is to understand how multiculturalism along with multilingualism contribute to the development of intercultural communicative competence in the context of teaching English to the learners whose mother tongue is Chinese not only in the PRC but the RF as well, i.e. in two big countries of the Eurasian continent, where official languages and the languages spoken by the main part of population are other than English. The conducted research was also aimed at analyzing the patterns of teaching English in the context of intercultural communication for students of undergraduate and postgraduate programs at the Harbin Institute of Technology and SPbSU (in linguistics), including the standards of the Harbin Institute of Technology in the field of language education (curricula and syllabi). 


\section{RESEARCH METHODOLOGY}

The research was conducted according to the following procedure: 1) establishing the theoretical framework of the research, 2) collecting empirical data in the two higher educational establishments through a series of performed surveys and interviewing relevant groups of respondents (faculty and students), 3) analyzing the data collected, and 4) presenting the findings.

The researchers from Saint Petersburg State education visited the Harbin Institute of Technology invited by the HIT administration and together with the Chinese colleagues, namely professor Liu Changyuan and the Dean of the School of Foreign Languages of HIT Kedong "Roy" Liu to fulfil the following goals: 1) to share the existing experience of teaching intercultural communication in Saint Petersburg State University at the Faculty of Modern Languages and to interview the staff to find out the practices of teaching English for intercultural communication in the HIT as a representative of a higher professional education of the PRC.

\section{THEORETICAL BACKGROUNDS}

The theoretical backgrounds of the research confined to the concept of internationalization of higher education institutions in the field of relevant language pedagogy considering the concept of synergy within the framework of the theory of intercultural communication as the theoretical base for the processes of internationalization of higher language education. This included closer look onto the notions of multilingualism form the perspective of Non-Native English-Speaking Teaching approach (NNEST) in language pedagogy for higher educational institutes (HEI).

The notion of synergy has been in use since ancient time when the effect of working together compared to individual performance was widely recognized and appreciated. Afterwards the concept acquired more salient recognition and impact, but was often viewed in a technical context denoting mostly the results obtained by the system, as a whole, not by any of the components acting individually. The synergetic effect or the achieved results were understood as the non-linear phenomenon of producing unpredictable value through cooperation. In language education it was considered within the framework of its influence learning and acquisition by a number of scholars striving to realize and define the factors that accelerated and intensified the cognition processes (Passfield 2002; Bransford, Vye et al 2005, Hodkinson, Anderson et al 2007). By the beginning of XXI century the idea of synergism had gained popularity, which partially predetermined a steady academic interest towards its influence on interaction between nations of the different languages and cultures.

The theory of intercultural communication began to shape with the arising interest to the communication between people as a general phenomenon. The academic interest of language pedagogy focused on the foreign languages before, shifted towards teaching and learning English, as the major tool of communication between nations whose mother tongues are different from English. The concurrent fields such English as lingua franca, comparative analysis, cultural and socio-cultural theories secured their positions as important aspects of the intercultural communication (Crystal 2003; Kachru 1997; Canagarajah 2013).

For example, there was a keen interest to the negotiations and other different forms of encounters in the Russian Federation in the 90s and zero years. Despite the fact that the 
native language of the parties to negotiations in the considered communication was different from English, both parties used it as the major instrument to cover the issues of the value for the participants. The grounds of the interest were predominantly economic, as those were the business and commerce that served the triggers and promoters of those forms of interaction. Not only were speaking skills required for the interaction in these contexts, but this negotiation process also encouraged the fastest possible development of formal writing skills, (i.e. academic writing and business correspondence) which also helped the communicants confirm and fix important details, clear up misunderstandings, etc.

These considerations conquered the minds of academics and the theory, which started with the papers of Michael Halliday, Anna Wierzbicka and the papers of the Moscow School of Semantics under the leadership of Jurij Apresjan, developed into an academic discipline exploring cultural aspects of any language, but with English as a particular case, in the process of communication.

Currently, the studies in the sphere of various cultural and social environments mapping the manifestations of cultural impact onto communication patterns are gaining momentum. Analyzing the impact of culture on the patterns of international communication the scholars were intensively exploring the forms it took in various social, ethnic religious and educational contexts (Kim, Young Yun 2001).

The major inherent thesis of the theory was that culture determines the way individuals encode and decode the exchanged meanings. It entails the interest to the information transmitting channels that the parties to the act of the intercultural communication use to convey and encode these meanings and the mechanisms that help them to receive and decode the messages. Any communication means interaction of at least two parties. Even within a multiparty communication (a polylogue), however, the basic unit still remains bilateral. Therefore, the analysis of intercultural communication in the context of the synergy of multilingualism and multiculturalism is to be rooted in the nature of a dialogue.

The major researcher of dialogism Mikhail Bakhtin (1895 - 1975), who is often referred to as the father-founder of the communication theory studying the phenomenon focused on the interaction and underscored its value for the humanity. Baxter puts it as follows: "Bakhtin's dialogism opens up space for communication scholars to conceive of difference in new ways," meaning they must take the background of a subject into consideration when conducting research into their understanding of any text. This aspect of Bakhtin's theory is important as "a dialogic perspective argues that difference (of all kinds) is basic to the human experience" (Baxter, 2006:101).

Thus, the theory of intercultural communication in the context of research as the theoretical mainstay was to map the manifestations of cultural impact onto communication patterns in the sphere of language education for intercultural communication of future professionals, i.e. teaching international or global English. The multiple implications in using the English language as an international or global one are accentuated by a considerable number of scholars studying the evolving problems and opportunities within the framework of the intercultural communication theory (Crystal 2003, Kachru 1997).

Bearing in mind the differences between the language systems from the viewpoint of the comparative analysis, first and foremost the research was centered upon the dialogue of language pedagogy cultures dealing with the necessity to foster communicative competence in English of digitally-savvy generation of students in two outstanding educational institutes that due to their status in homeland education are seen as bright representatives of the relevant culture. It should be noted that the English language education was analyzed in two states 
where mother tongues are different from English and where, as well as in many other countries of the world today, there is a certain understanding of cultural influence of English on the learners' cognition and perception, and eventually on their personal values and beliefs.

Initially multilingualism was the matter of academic focus mostly in neurology and the issue of brain mechanisms was number one in the research into the theory of bilingualism as the number of international families came to front after the WWII (Penfield, Roberts 1959; MacNamara, Krauthammer, Bolgar 1968). In 1990s the research acquired social shades and shifted to the issues of multiethnic communities in the countries where the populations used different languages in the process of interaction (Webb 1999).

However, with the advent of globalization it was the lingua franca issues that were the first to be explored. Besides, one or another language system quite often was compared to the system and communicative means of the English language as the latter was gaining more and more influence in the globalizing world. One of the reasons for English to become the major source of intercultural communication was the number of its users for that very purpose.

Viewed from this perspective, the Chinese language could challenge the English language as most widely spoken one, with around $16 \%$ of the world population speaking some form of Chinese. However, the written form of the standard language is based on the Chinese characters, which, on the one hand, helps the literate speakers in China understand each other and, on the other hand, complicates learning Chinese and using it as an international means of communication. According to N. Ostler research (2010) while nearing English in the number of people speaking Chinese as a mother tongue, the Chinese language lags behind significantly when considered as lingua franca with the proportion 812 thousands of English-users against only 178 thousand for Chinese (Ostler, 2010). The latter reason motivates educational institutions in China to introduce English as an academic subject into their curricula.

Concerning the group of students who acted as the respondents in Saint Petersburg University, the first language of the respondents was the official Chinese. The students' cohort was quite representative as they were from different Chinese cities and provinces (Bejing, Harbin Shaghai, Urumqi, Chengdue, etc). The specificity of interaction between the Russian and Chinese language systems was of secondary importance for our research, as the students were learning English within the NNEST model, i.e. with the teachers whose mother tongue was not English. It was rather the culture of educating and learning in both educational institutions that was important for the needs of the investigation. The modes of teaching and learning compared were to reflect the matter of multiculturalism.

\section{Multiculturalism in Higher EduCATion}

Multiculturalism is the concept usually viewed in the paradigm of countries or entities that sort out the problems of coexistence of different nations and ethnicities on the said country territory or as the problems of immigrants in the receiving states. The concept of multiculturalism within the subject to consider is closer to the first aspect of the paradigm and consists in finding those positive aspects of two educational cultures commonalities and differences that are presumably beneficial to the internationalization of higher education and higher education language pedagogy. 
The language teaching cultures of Russia and China are assumed specific as they are intercultural inside the countries and have specific educational practices. Nevertheless, the task was to understand what is necessary to promote internationalization of higher education in these two countries.

Initially the notion of multiculturalism has been used as an umbrella term to present a wide range of interests of the groups, discriminated in their societies such as African Americans, women, LGBT people, and people with disabilities (Taylor 1992). The contemporary multicultural discourse is more focused on immigrants' issues and diversifying school curricula to recognize their rights and secure access to the education.

Although multiculturalism is often associated with "the politics of difference," or "identity politics," most of progressive researchers are determined to revalue disrespected identities and revise the prevailing patterns of representation (Gutmann 2003, Taylor 1992, Young 1990). In our research we focus on multiculturalism viewed as a system of values and beliefs of teachers and learners regarding teaching/learning English in the light of its possible benefits for internationalization, rather than into the differences in the governmental language education policies.

The second, not less important multicultural aspect was studying China's and Russia's cooperation models to facilitate systematic integration into some international commonlyshared values of education. Most papers devoted to the issues of internationalization usually approach the subject in terms of educational services and mutual impact of educational systems and institutions of different countries on each other. This research prioritizes the role of language pedagogy and teaching International English or English for intercultural communication in such a multi-aspect process as the one of internationalization of higher education in the context of the two biggest world's systems. The idea of internalization of education in the context of educational systems of the two biggest countries on the Eurasian continent theoretically has been confronted for the first time.

The review of the systems provides some information necessary for the understanding possible advantages gained through cooperation and synergetic effect of these activities. The first systematic feature to be recognized is that both higher educational models rely on the tier system with three levels:1) undergraduate studies or doing the Bachelor Degree (usually 4 years 2) master studies or doing Master Degree which is required for gaining a higher-level positions in such spheres as behavioral health, education and engineering (usually 2 years) and 3 ) doctoral studies for $\mathrm{PhD}$ degree, which normally take about three years but for foreign students might be more protracted up to five or even six years. The advantages and the genesis of such system of higher education were presented in a number of research papers (David 1972; Altbach, Gumport, and Berdahl, 2011). This system is the most spread one nowadays, with some little variations of the stages duration (sometimes the first stage may last for 3 years).

Another feature to be observed nowadays is the trend towards convergence of higher educational institutes so that to provide a double diploma relevant for operating both in the RF and PRC. One of the most exemplifying arguments for this is the cooperation between Harbin Institute of Technology and Saint Petersburg State University. Although the history of Sino-Russian cooperation between the two institutions dates back to 1920s, it was only not long ago when the cooperation intensified and there has been observed the growth of the activities with a number of the most recent addition such as: a cooperation agreement signed by the representatives of the two universities (2014), opening the SPbSU representative office in the HIT (2018), and the most recent agreement on 
building a university campus in China (2019). The latter was signed at the 20th meeting of the Russian-Chinese Intergovernmental Commission on Humanitarian Cooperation by the Rector of St Petersburg University Nikolay Kropachev and the President of Harbin Institute of Technology Zhou Yu. (SPbSU website). The first steps of cooperation in the field to be mentioned include establishing a number of joint research centers, e.g. the Centre of Plasma Physics and the Centre for Environmental Safety and Russia-China Legal Centre, which provided a ten-fold rise in academic mobility.

Internationalization of the substance of teaching, learning, and research being the underpinning basis of this cooperation has been registered not only into teaching and learning of science and technology but also into the language pedagogy. One of the kind was the investigation of SPbSU Professor of Russian as a foreign language N.V. Fedotova (2017), that was later presented in the paper describing the project undertaken by a team of $\mathrm{SPbSU}$ researchers "Implementing Sino-Russian Educational Programs for Training Chinese Engineers" (However, the project was focused on teaching Russian to those students who arrive to Russia for technical knowledge, i.e. it aimed at increasing "the efficiency of teaching standard Russian language and technical Russian parlance to Chinese non-linguist students both inside and outside Russian-speaking environment and to prepare students for the exchange education in Russia" (Fedotova, Solovijeva et al 2019:166).

If N.V.Fedotova's and her team project was to increase the efficiency of teaching Russian to Chinese students, the research conducted by the authors of this paper a year after (November, 2018) was focused on internalization of Sino-Russian higher education systems in the sphere of language education - the modern challenges of teaching and learning English for intercultural communication. To specify on details, the study scrutinized the opportunities of internationalization of higher language education in teaching English by NNEST instructors offset by the role of foreign language knowledge for intercultural communication. The main areas of studies were the following:

1) teaching intercultural communication through ESP/EAP as the major tool of global information exchange in academic community in the RF and PRC;

2) learning intercultural communication through digital culture and environment of students from PRC to understand the factors to be employed for greater efficiency of higher language education.

Both areas synergized were to secure a more efficient model of internationalization. The authors followed the patterns presented by Barbara Kehm and Ulrich Teichler in their research into internationalization of higher education (Kehm, Teichler, 2007). We prioritized transferrable skills for on-the-job utilization of knowledge acquired during the course of studies to increase the characteristics of the specialist's value for the economies of the RF and PRC and their bilateral interaction and involvement into global economy. The goal was to explore the digital era influence on learning English for intercultural communication as the growth of digital economies necessitated a study of their language and information needs in the digitized world.

\section{INTERNATIONALIZATION OF EDUCATIONAL SYSTEMS THROUGH TEACHING ESP/EAP FOR INTERCULTURAL COMMUNICATION}

In spite of the trend of soaring interest of Russian young people to studying Chinese and vice versus (the desire of Chinese students to study Russian), the knowledge of English still means a lot in the global academic communication culture and retains its 
position as lingua franca, therefore, the English Language Proficiency still remains a prioritized necessity. To understand the nature of teaching and learning models there was conducted a number of surveys aimed at to find out: 1) what the teaching prerequisites in both universities are; 2) what language and skills are focused on in teaching; 3) whether the ESP/EAP is taught and, if, it is what its forms are. The survey was conducted both among the teachers of the School of International Relations of Saint-Petersburg State University and the faculty of the School of International Studies in HIT who presented their overall practices of teaching. To present the most recent development of ESP/EAP teaching in the Faculty of Modern Languages, there was an introductory talk on the role and content of teaching ESP/EAP exercised by the departments of English in the Science and Humanities within this university structure.

The first step within the research was to map out the initial conditions of teaching English for Intercultural Communication at both faculties in Russia and China. For the purpose the faculties of two universities were to answer a number of questions designed by the research team. The analysis of data collected among the Faculty of the International Studies and at the School of International Relations displayed the existing common, variable and different features in the practices of teaching ESP/EAP as the major instrument of intercultural communication of the modern academic community and to consider them for both educational institutions in terms of internationalization in higher education.

The group of teachers consisted in eleven teachers (11) from the Department of English the School of International Relations of Saint Petersburg State University and twelve (12) teachers from the School of International Studies of the Harbin Institute of Technology, most teaching English at the Bachelor, Master and Doctoral levels took part in the survey. The results are presented in Table 1.

Table 1 Language Teaching Practices at SPbSU (Russia) and HIT (China)

\begin{tabular}{|c|c|c|c|}
\hline \multicolumn{2}{|l|}{ Parameter } & SPbSU (Russia) & HIT (China) \\
\hline Teachers'age & $\begin{array}{l}30-40 \\
41-50 \\
51-65\end{array}$ & $\begin{array}{l}2 \\
8 \\
1\end{array}$ & $\begin{array}{l}3 \\
7 \\
2\end{array}$ \\
\hline \multicolumn{2}{|c|}{ academic hours a week } & $20-24$ & $8-12$ \\
\hline \multicolumn{2}{|c|}{ number of students in a language group } & $10-15$ & $20-30$ \\
\hline \multicolumn{2}{|c|}{ NEST vs. NNEST teachers } & $\begin{array}{l}2 \text { mentioned the } \\
\text { desirability of a native } \\
\text { speaker's teaching at } \\
\text { post-graduate and } \\
\text { doctoral levels }\end{array}$ & $\begin{array}{c}\text { Strong NNEST } \\
\text { position }\end{array}$ \\
\hline
\end{tabular}

The data analysis enabled the research team to picture higher education teaching of ESP/EAP. The average age of participants was within the scope of 41 to 50 although there was registered a slight preponderance in favour of younger than average and older than average teachers in the HIT group of teachers. The next difference concerned the teaching hours that in the case of Russian HEI was 20-24 academic hours a week on average, while in the HIT it was just 8-12 academic hours a week. The number of students in an average group in a language group of SPbSU is $10-15$, while in HIT it is 20-30 students. The most general 
qualitative characteristics of students studying in both universities were nearly impossible to define as the respondents used different approaches to the assessment of students level of proficiency to get enrolled: the Russian teachers assessed the students proficiency at the entrance examination in terms of CEFR levels, while their Chinese colleagues either mentioned Nation-Based Exam score securing enrollment or attempted to define the entrance requirement in the terminology of an US HEI using the concept "College Entrance Examination" or just a placement test for those whose professions do not prioritize English.

In terms of internationalization of HEIs the most indicative convergent trend turned out to be the attitude towards NNEST vs NEST teaching practices. Although the faculty of SPbSU suggested having a NES teacher at the second and third levels of higher education (Master and Doctoral Studies). Their Chinese counterparts also supported NNEST approach referring to better mutual understanding between teacher and learner in a monocultural group and NNEST teachers' capability to comment on the cultural differences between overall global English language based culture and the traditional culture of the most people in China.

\section{LEARNERS' DigitAL ENVIRONMENT AS INALIENABLE FEATURE OF INTERNATIONALIZATION OF HIGHER LANGUAGE EDUCATION IN RUSSIA AND CHINA}

With globalization processes embracing all spheres of life including education and language education in particular, the research team was to consider the learners opportunities for intercultural communication, bearing in mind their heavy reliance on the Internet. The often heard criticism of students spending too much time online gradually ceasing, the researchers paid due respect to the online habits of learners. These habits were regarded as the access to the English language in real-time communication, greater exposure to the English language for intercultural communication so that to consider opportunities provided by these habits for internationalization of education and especially for language education.

Focusing the question of the synergy of multilingualism and multiculturalism for internationalization of HEI language education the particular attention was paid to the following: 1) the constituents of learner's digital environment, 2) their use of English in this communication, and 3) possible implications of their online habits for the internationalization of the higher education and language pedagogy. In particular, the study was to outline the existing forms of online intercultural communication, mostly in terms of the information exchange in communication and the search of the needed information as an inalienable parts of learning English for intercultural communication. That involved putting forward a hypothesis that online presence of learners contributes to the internationalization in higher education as it facilitates the learners' engagement into intercultural communication as one of its most salient features: 1) it can be achieved through analyzing the practices underlying studies within the both considered parties, i.e. groups of learners, 2) the analysis of these practices will definitely contribute to the internationalization of higher language education.

To emphasize the necessity of changes in the content of English language education to prepare specialists for digital economies we offered a number of sentences describing new practices existing in a society rich in technologies both to teachers and their learners and asked them to paraphrase them to display their understanding. The following sentences were offered for teachers and learners. The digital practices neologisms provided their interpretation given in italics: 
1) "My date was terrible last night, so I used a fakersation to leave early."

Interpretation: My date was terrible so (I lied) that a have a reason to leave

2) "His stories are so hi-res, it feels like I'm there."

Interpretation: His stories are so (detailed) it feels like I am there

(hi-res derives from high-resolution)

3) "My moo-q is off today - I didn't get enough sleep last night."

Interpretation: My mood and IQ are off today - I didn't get enough sleep last night.

4) "I got commjacked when I connected to public wi-fi ..."

Interpretation: My logins and password were stolen when I used public wi-fi...

The results of the experiment appeared to be indicative. Thus, nearly all teaching staff of both educational institutions got puzzled with the task and manage the first sentence only, while their learners only fail to interpret "moo-q" in the third sentence.

For the purity of the outcomes the research group suggested the learners both in the HIT and SPbSU to answer the following questions: 1 ) what students in both countries view as their digital environment, 2) whether they make use of it to facilitate their learning and learning languages in particular, 3) what is being done by higher educational institutions to cater for this in the context of multiculturalism and multilingualism.

The final idea was to understand whether anything and what exactly should be changed in both higher education institutions so that to improve learners' capacities by means of making use of digital environment. For the purpose the students in both universities were provided with questionnaires aimed at finding out whether digital environment is beneficial for their intercultural communication in different real-time locations and to map out the steps to use it in the process of learning:

1) what constituents of their digital environment they prioritize;

2) what their instruments of intercultural online communication are;

3) what facilitates communication in digital environment.

Saint Petersburg State University group embraced seventeen respondents, all citizen of the PRC, primarily 19-20 years-aged, undergraduates of the program "The English Language and Literature" (hereinafter referred to as R-group). At the same time the sample in the Harbin Institute of Technology consisted of two groups of students of the School of International Studies, also both 19-20 years old, all doing their bachelor degree. All HIT students were viewed as a single group of respondent (further referred to as C-group).

First of all, students of both universities said that their digital environment is provided by their mobile phones where they have the opportunity to exchange messages with a number of friends: read their posts and post information themselves, watch short and funny videos and post their own videos downloaded or hand-made, listen to the selections of the songs or exercise a random search for music they find appealing. Therefore, there was a focused analysis to see the scale and the aspects of digital behavior. The data-analysis (as it goes from Figure 1, Figure 2 below) first facilitated more focused evaluation of social networks selection, search engines for surfing the web and their attitude towards the internet-based communication in general. 

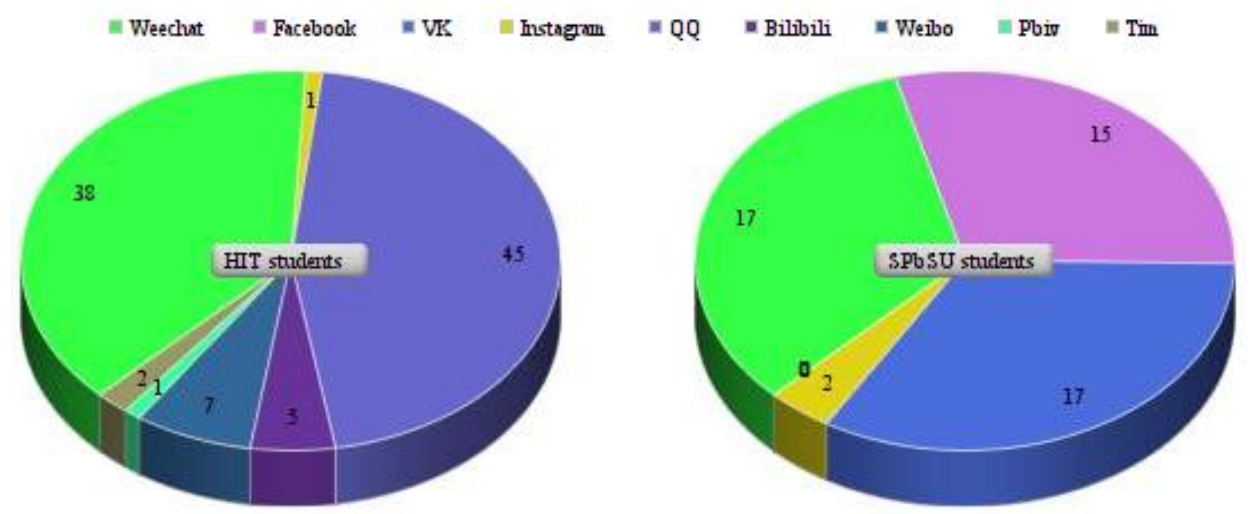

Fig. 1 R-Group and C-Group Digital Environment Evaluation Data (social networks)
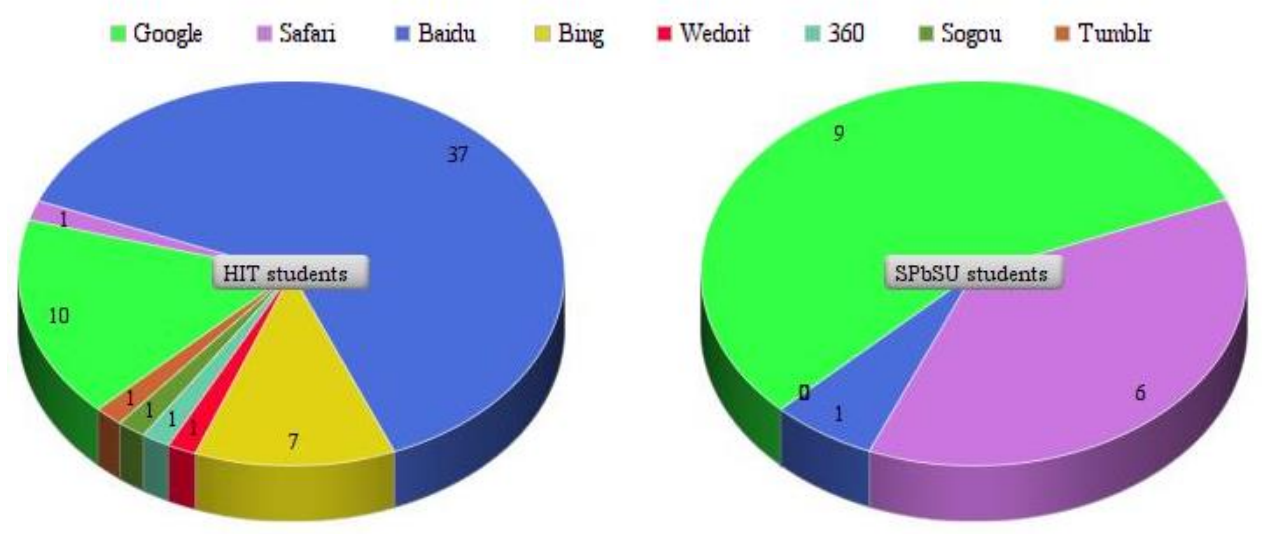

Fig. 2 R-Group and C-Group Digital Environment Evaluation Data (search engines)

The analysis reveals that both groups are heavy users of social networks, which means that most of their communication is mediated by networking within their digital environment. At the same time the collected data demonstrate not only the greater variety of local social networks in the PRC, but also the existing opportunity to exercise communication in one of them. Although due to the Great Firewall Internet policy such networks as VKontakte and Facebook are not officially allowed, there is still another way to communicate which is within a Chinese social networks WeChat. As Twitter not officially accessed in the PRC either, WeChat is a micro-messenger which provides for multi-purpose messaging, social media and mobile payment app developed by Tencent (a Chinese multinational holding company which trough its affiliations promote different internet services and products) (Tencent official site).

The R-group, according to the collected data, pertained the patterns more typical for the youth of Saint-Petersburg, Russia. However specific these practices might be and reflecting the European part of the RF, the showings displayed that all respondents have VK accounts, and only two of 17 respondents are not registered on Facebook, with all that R-group respondents being registered members of WeChat. 
The C-group confirmed the WeChat popularity in PRC (38 out of 58 respondents), however, according to the data collected, the QQ social network also a new breed of instant messengers is much more popular (45 out of 58 respondents). Social aspect considered the popularity of the messenger among the students is the main argument in favour of new digitized intercultural communication. At least the international version of the QQ website (the abbreviation initially derives from ISQ) maintains that the service is to provide multinational communication, uses live translation "to sort your problems out when you need to overcome cultural distances'. The service generally is stated to have "over $1,000,000,000$ registered users across $80+$ countries is available on all operational systems"

The third in popularity rating among the undergraduates and post-graduates in China turned out to be the Weibo service. The name Weibo is the transliteration of the Chinese word 'weibo'(微博) which means 'microblog' and in March 2017, Sina launched its International Version.

The issues of search engines brought the specific results: the Chinese respondents demonstrated a considerable variety of the ways to find the necessary information, while their counterparts in SPbSU stated that they use only Google-search (with one respondent mentioning Baidu).

When characterizing their digital environment R-group maintained that the main component of their digital environment is social networks because they meet their needs in the information exchange and search engines as they facilitate, aggregate and accelerate the search of the information they need for their life (shopping, getting around etc). It was a discovery that finding a number of advantages of search engines the respondents on both sides did not mention the usefulness of the engines for their studies.

\section{CONCLUSION}

The investigation brought the results which were rooted in the theoretical tenets of intercultural communication and the sociolinguistic aspect of multilingual, multicultural grounds of the theory for internationalization of higher language education.

The idea of an obligatory course of English was revisited within the context of the two biggest countries both speaking languages having a regional status, i.e. covering the needs of geographically relevant communication. Both higher education authorities confirm the importance of learning English for the graduates, having introduced English into the syllabi. In the light of the graduates joining labour market English is seen as an instrument to produce and share as well as perceive and interiorize. The surveys have revealed that the faculties both in Russia and China have adopted a three tier model, however there is a difference in the number of academic hours and number of students in a group, that the idea of individual trajectories of learners is not used by the English teachers in Harbin Institute of Technology, but both have National Examinations which are labelled differently. Both institutions claimed teaching ESP/EAP, often not as a separate course, however, the colleagues from Saint Petersburg shared the experience in developing an online course on Academic Writing in English.

At the same time the potential for internationalization in higher language education was confirmed through a series of surveys into the intercultural communication of learners. In the course of the investigation all of the learners recognized the role of social networks for intercultural communication and the role of search engines in substantivizing this communication. Although, it turned out to be impossible to find out how much time a day 
R-group and C-group tend to spend browsing the Internet for information, nevertheless the data indicated that the Internet is intensively used for learning purposes by both groups.

Surprisingly, C-group cited a greater number of existing social networks with WeChat, QQ and Weibo as the most popular. Twitter-type micro-blogging apps in China are popular, while in Russia Twitter is not as popular as Instagram, VK and Facebook (which are not available in the PRC). However, Chinese Weibo has recently opened an international version of the service in English that means for not speaking Chinese uses.

Yet, the Chinese and Russian higher language education might take note of the opportunities to develop intercultural communication through the synergy of interstate cooperation aggregated by unifying teaching practices, which should establish a methodology employing the potential of social networks and browsers for language studies, exploit their popularity intercultural communication and promote integration in the sphere of higher education language learning.

\section{REFERENCES}

Altbach, Philip G., Patricia J. Gumport, and Robert O. Berdahl, eds. 2011, American higher education in the twenty-first century: Social, political, and economic challenges. JHU Press.

Baxter, Leslie 2006. Communication as...: Perspectives on theory. Thousand Oaks, CA: SAGE. p. 101.

Bransford, John, Nancy Vye, et al. 2005, "Learning theories and education: Toward a decade of synergy." URL: http://ilabs.washington.edu/kuhl/pdf/2006_Bransford_Vye_ etal (19 September 2019).

Canagarajah A. Suresh. 2013. Literacy as Translingual Practice: Between Communities and Classrooms (ed.) London and New York, Routledge. pp. 256

Cockerell, Isobel (9 May 2019). "Inside China's Massive Surveillance Operation" URL: https://www.wired.com/story/inside-chinas-massive-surveillance-operation/ (25 September 2019).

Crystal, D., 2003. English as a global language, Cambridge University Press

David, J., 1972. American higher education. New York: McGraw-Hill.

Fedotova, N.L., Solovyeva, E.B., et al. Implementing Sino-Russian Educational Programs for Training Chinese Engineers // ITC. 2019. №2 (95). URL: https://cyberleninka.ru/ article/n/implementing-sino-russian-educational-programs-for-training-chinese-engineers (1 September 2019).

Gutmann, A., 2003. Identity in Democracy, Princeton: Princeton University Press

Hodkinson, Phil, Graham Anderson, et al. 2007. "Learning cultures in further education." Educational Review 59, no. 4: 399-413.

Kachru, B. B., 1997. World Englishes and English-using communities. Annual Review of Applied Linguistics, 17, 66-87.

Kehm, B. M., Teichler, U., 2007. Research on internationalization in higher education. Journal of Studies in International Education, 11, 260-273.

Kim, Young Yun. 2001. Becoming Intercultural: An Integrative Theory of Communication and Cross-Cultural Adaptation, Thousand Oaks, Calif. : Sage Publications, Inc.

MacNamara, J., Krauthammer, M., and Bolgar, M. 1968. Languageswitching in bilinguals as a function of stimulus and response uncertainty. J. Exp. Psychol 78: 208-215. 
Ostler, Nicholas. 2010. The last lingua franca: English until the return of Babel. Bloomsbury Publishing USA.

Passfield, Ron. "Creating innovation and synergy through a parallel action learning structure." The Learning Organization 9, no. 4 (2002): 150-158.

Penfield, W., and Roberts, L., 1959. Speech and Brain Mechanisms. Princeton Univ. Press, Princeton, New Jersey.

Taylor, C., 1994, "The Politics of Recognition," in Multiculturalism: Examining the Politics of Recognition, A. Gutmann (ed.), Princeton: Princeton University Press.

The official website of SPbSU: http://english.spbu.ru/news/3198-st-petersburg-university-andharbin-institute-of-technology-are-to-build-a-joint-campus-in-china) (15 September 2019).

The official website of Tencent https://www.tencent.com/en-us/index.html (18 September 2019)

Titova S.V. Avramenko A.P. 2014, Mobil'noye obucheniye inostrannym yazykam. Izdatelstvo Ikar (Titova S.V. Avramenko A.P. "Mobile learning of foreign languages."Moscow: Icarus Publishing House, 2014).

Webb, Vic., 1999. "Multilingualism in democratic South Africa: The over-estimation of language policy." International Journal of Educational Development 19, no. 4-5: 351-366. Hammoud, Salah-Dine. "Mutilingualism, Cultural Identity, and Education in Morocco." (2004): 143-147.

Young, I.M., 1990. Justice and the Politics of Difference, Princeton, NJ: Princeton University Press. 